prostate and vagina respectively, and the last two between the parotid and the ovaries.

In none of these cases was there any reason to believe that the peritoneum was implicated, and in the first two the affections were evidently secondary parotitis, not mumps. Nor do 1 think that Dr. Tayler's septic theory can be admitted except in the first case.

1 cannot help thinking that ovaritis would be found more frequently associated with mumps if it were carefully inquired for, as we know young women are very apt to conceal pains occurring in those regions unless expressly questioned about them.

I am, Sir, yours truly,

Highbury-place, Jan. 1886. ARTHUR J. CRIBB, M.D. Lond.

\section{PROSTATIC CASTS.}

\section{To the Editor of THE LANCET.}

SIR,- In a paper recently read by Sir Andrew Clark, at the Clinical Society of London, on a "Case of Acute Prostatitis, with Discharge of Hyaline Cylinders resembling Renal Cylinders," and to which your annotation of Jan. 16th directs further attention, the author remarks: "These cases with prostatic casts in the urine may be only curiosities of medical experience, but since in none of the standard works on urinary affections, and in no monographs dealing with diseases of the prostate, can any reference be found to the discharge of hyaline cylinders in prostatitis, and without careful examination they might very easily be mistaken for cylinders originating in the kidney, $I$ have thought the case was of sufficient importance to bring it before the notice of this Society."

Sir Andrew Clark is mistaken in supposing that he has made an original observation. In two papers published by me in THE LANCET (Oct. 14th and 21st, 1882) on Prostatorrhoea-a by no means infrequent disease-a case is referred to in which prostatic casts were believed to exist in the urine, and an illustration of the deposit is given, while the subject is referred to, not by any means as an original observation, but as one generally recognised. In his book on the "Male Sexual Organs," S. W. Gross, of Philadelphia, in the chapter on Prostatorrhoea, remarks: "If the patient be requested to pass the first two or three ounces of urine in a glass, that fluid will be found to contain delicate filiform shreds, which are sometimes more than half an inch in length, and which are muco-purulent casts of the follicles and ducts of the prostate. This highly characteristic sign of the affection, when considered in connexion with the local signs and the minute examination of the discharge, the composition of which has already been sufficiently considered, is quite sufficient to establish the true nature of the trouble." Delafosse (Paris, 1885) gives an illustration of these casts, and they are described by many other authors, to whom it is superfiuous to refer.

Glasgow, Jan. 25th, 1886.

$$
\text { I am, Sir, yours \&c., }
$$

D. Campbert Black.

\section{THE METROPOLITAN ASYLUMS BOARD.}

\section{To the Editor of THE LANCET.}

SIR,- - I have read with interest a leading article relative to the Metropolitan Asylums Board in your issue of the $23 r$ inst.

The evils and abuses likely to arise under the system of divided or multiple and co-ordinate authority hitherto exercised in the asylums and hospitals under the control of the managers appear within the last few years actually to have arisen, and some of them hare been sufficiently demonstrated in the late Eastern Hospitals inquiry. The question therefore presents itself to the managers for their consideration, whether, if not already done, the time has not now arrived when free effect should be given to the order of the Local Government Board, dated Feb. 10th, 1875, by which sufficient authority is vested in the medical superintendent to enable him to control in their duties the officer's attendants and servants of each establishment, if duly supported by the managers. This step would, at all events, serve the one good purpose of enabling the managers with fairness to fix responsibility.

I am, Sir, your obedient serrant,

Harley-street, W., Jan. 1886.

JAMES ADAM, M.D.

\section{MANCHESTER. \\ (From our own Correspondent.)}

MEDICAL SOCIETIES.

THE annual meeting of the Medical Society evidenced a flourishing condition of its affairs, the number of members being 242 , whilst the treasurer was able to show a balance on the right side of more than $£ 100$ on the year's receipts and expenditure, whilst there is invested in the name of the trustees, on behalf of the Society, $£ 1110$. Another member of the surgical staff of the infirmary, Mr. Hardie, has been elected president for the current year, this making the sixth year in succession that the presidential chair has been occupied by one of the staff of the Royal Infirmary. It would have been good policy on the part of the committee to have nominated someone outside the charmed circle, for there is a widespread feeling amongst many members of the profession that this distinction is confined rather too much to the inflrmary staff. The Medico-Ethical Society has nominated Mr. Walmsley for re-election as president, thus following the precedent of the previous two years, when Dr. Lloyd Roberts held the same office.

\section{HEALTH LECTURES}

The popular lectures given this winter on sanitary and popular medical subjects are more numerous than usual. Before Christmas, Miss Emily Hall delivered a very useful series on Personal and Domestic Hygiene. Then we have the annual course delivered under the auspices of the Sanitary Association, which has again this year arranged a series having a certain amount of connexion the one with the other; they all relate in some manner to food or drink, the different lecturers taking each a special article of diet. And, lastly, a course is being delivered at the Ancoats Hospital by the staff of that institution, much resembling the ordinary ambulance course. Mr. Bishop delivered the first on Surgical Emergencies, and Dr. Niven the second on Medical Emergencies. There will shortly be a vacancy on the staff of this institution, owing to the appointment of Dr. Niven to the post of medical officer of health to the neighbouring borough of Oldham. A very interesting paper on the sanitary work carried on by the Health Committee of the Corporation was lately read by Mr. Whiley, the superintendent of the department, before the Statistical Scciety. The magnitude of its operations is shown by the expenditure on this work, which amounts to no less than $£ 86,000$ per annum, and another $£ 60,000$ is about to be expended upon a sewage farm on Carrington Moss. Municipal work in Manchester is carried on in no pigmy style: the Water Committee are bringing us water from the lakes of Cumberland, at an estimated cost of something like a quarter of a million sterling, the engineering skill shown in this undertaking rivalling the work of a similar nature for the supply of water to Ancient Rome.

\section{EDUCATIONAT MATTERS.}

In all probability we are to have an important experiment tried in connexion with our Board Schools, A deputation from the Manchester and Salford Trades Council waited upon the School Board at their last meeting, pointing out the great importance of attempting to attract young people, boys and girls who have just left school, to evening classes; seeing that it was between the years of thirteen and eighteen that young people acquired those habits which more or less affected their whole after-life, they asked the Board to assist them in endeavouring to counteract the attractions and facilities which existed in all large towns for young people to form idle and vicious habits. Allusion was made to work of a similar kind being done in Nottingham, and the Board promised their careful consideration of the matter. At the last meeting of the Salford School Board there was rather a lively passage of arms between some of the members over the management of the industrial schools. If the statements made be correct-viz., that the children have to attend at 6 A.M., that little children of ten jears of age have to clean the floors, and that their dinner consists of suet pudding six days in the week and pea-soup on the sixththey are certainly not being reared as hothouse plants.

BCTTERINF.

It cannot be said that the Adulteration of Food and Drugs Act is a dead letter here, for scarcely a week passes without 